\title{
Capacitive Deionization for the Removal of Paraquat Herbicide from Aqueous Solution
}

\author{
Tusekile Alfredy $\left(\mathbb{D},{ }^{1,2}\right.$ Joyce Elisadiki $\mathbb{D}^{3},{ }^{3}$ and Yusufu Abeid Chande Jande $\mathbb{D}^{1,2}$ \\ ${ }^{1}$ Department of Materials and Energy Sciences and Engineering, The Nelson Mandela African Institution of Science and Technology, \\ P.O. Box 447 Arusha, Tanzania \\ ${ }^{2}$ Water Infrastructure and Sustainable Energy Futures (WISE-Futures) Centre, The Nelson Mandela African Institution of Science \\ and Technology, Nelson Mandela Road, Tengeru, P.O. Box 9124, Arusha, Tanzania \\ ${ }^{3}$ Department of Physics, College of Natural and Mathematical Sciences, University of Dodoma, P.O. Box 338 Dodoma, Tanzania
}

Correspondence should be addressed to Yusufu Abeid Chande Jande; yusufu.jande@nm-aist.ac.tz

Received 1 July 2021; Revised 12 September 2021; Accepted 23 September 2021; Published 8 October 2021

Academic Editor: Senthil Kumar Ponnusamy

Copyright (c) 2021 Tusekile Alfredy et al. This is an open access article distributed under the Creative Commons Attribution License, which permits unrestricted use, distribution, and reproduction in any medium, provided the original work is properly cited.

\begin{abstract}
In comparison to other conventional methods like adsorption and reverse osmosis (RO), capacitive deionization (CDI) has only been investigated extensively for the removal of inorganic pollutants from water, demonstrating limited practicality. Herein, the study investigated the use of CDI for the removal of paraquat (PQ) herbicide from water by using commercial activated carbon (AC) electrodes. The CDI performance was examined as a function of the initial PQ concentration, applied voltage, flowrate, treatment time, and cycle stability testing in the batch mode approach. The applied voltage had a beneficial effect on the removal efficiency, whereas the removal efficiency of PQ declined as the initial PQ concentration increased. However, the electrosorption capacity gradually increased with the increase of initial feed solutions' concentration. The maximum removal efficiency and electrosorption capacity achieved at $5 \mathrm{mg} / \mathrm{L}$ and $20 \mathrm{mg} / \mathrm{L}$ PQ initial concentrations, an applied voltage of $1.2 \mathrm{~V}$, and $5 \mathrm{~mL} / \mathrm{min}$ flowrate were $100 \%$ and $0.33 \mathrm{mg} / \mathrm{g}$ and $52.5 \%$ and $0.7 \mathrm{mg} / \mathrm{g}$, respectively. Washing the electrodes with distilled water achieved sequential desorption of $\mathrm{PQ}$, and the process produces a waste stream that can be disposed of or treated further. Therefore, the CDI method is considered a promising and efficient method for removing organic pollutants from water including pesticides.
\end{abstract}

\section{Introduction}

The demand for safe and clean water has been rising as the earth's population keeps increasing. Activities that are associated with population growth have a great impact on environmental pollution as different compounds are released into the environment as a result of human and industrial activities [1]. Pesticides, hormones, food additives, laundry detergents, plasticizers, surfactants, wood preservatives, disinfectants, and flame retardants are examples of these contaminants discharged to the environment [2]. In recent decades, pesticides in agricultural activities are increasing to meet the food demand for population growth. The usage of various kinds of pesticides has contaminated all of life's necessities: food, water, and air [3]. Agricultural wastewater issues have gained much attention and become a burning issue because their management is still challenging. The release of agricultural wastewater into the environment without proper regulation poses a major hazard to human health and the environment in general [4]. According to Dulio and Slobodnik [5] around two (2) million tons of effluent is being discharged into freshwater, polluting water sources.

Paraquat (PQ) (1,1'-dimethyl-4,4' dipyridinium chloride) or methyl viologen, by brand name known as gramoxone, is amongst the commonly and widely used herbicide compounds in agriculture worldwide [6], and over 100 countries had been applying it since 1962 [7]. Paraquat is a broad-spectrum, nonselective contact herbicide used to suppress narrow leaf and broadleaf weeds in both nonagricultural and agricultural settings. It is applied in the cultivation of tobacco, rice, coffee, grapes, beans, apples, soybeans, sugarcane, and other crops $[8,9]$. 
Exposure to PQ can be extremely harmful to the body organs, including the lung, brain, muscles, liver, adrenal glands, and kidney, either accidentally or deliberately and even results in death $[10,11]$. Various studies reported on the linkage between Parkinson's disease and paraquat usage $[12,13]$. Paraquat can enter into the water supplies and is considered a threat to human health even at a low level. Because of the cationic charge present on the molecule, paraquat's (PQ) high solubility in water $(620 \mathrm{~g} / \mathrm{L})$ increased the contamination risk of PQ to water sources [14]. The maximum allowable PQ level in drinking water has set to be $0.01 \mathrm{mg} / \mathrm{L}[11,15]$. Thus, removing PQ from water and decreasing $\mathrm{PQ}$ poisoning is of great significance when it comes to water pollution. Therefore, the development of low-cost, high-efficiency technology for removing PQ from water is vital.

Pesticides and different organic matters have been removed from water using a variety of techniques including adsorption $[16,17]$, membrane separation processes [18, 19], photodegradation [20], and advanced oxidation processes [21, 22]. Because of its high removal efficiency, ease of design, and cheap operational cost, adsorption has been extensively explored among the methods listed above [4, 23-25]. Despite its interesting attributes, the adsorption process faces numerous challenges including a short lifespan due to low regeneration capacity [26] and usage of acid or alkali during the regeneration process which results in secondary water pollution [27]. Organic pollutants are removed effectively using membrane separation technology. On the other hand, membrane processes face challenges such as membrane fouling or deterioration, making them impractical and costly in terms of energy consumption, installation, and maintenance [28-30]. The photodegradation approach can degrade organic pollutants under ambient conditions by using visible light from the sun as energy and $\mathrm{O}_{2}$ in the air as an oxidant, as well as oxidation of organic compounds even at low concentrations [31-33]. However, the major disadvantage of this process is the insufficient sunlight utilization and ambiguous reaction mechanism [20]. Additionally, advanced oxidation processes (AOPs) have been successfully used to decompose many hazardous chemical compounds to acceptable levels at or near ambient temperature and pressure and produce no further hazardous byproduct or sludge that requires additional handling, but the techniques are capital demanding (costly) and require complicated chemistry to be tailored to specific applications, and in some applications, quenching of excess peroxide is required $[34,35]$. Therefore, technologies that will overcome the challenges of regeneration of adsorbents, fouling, and energy consumption in the water treatment arena are highly needed.

Capacitive deionization (CDI) is an emerging desalination method that is being investigated as an alternative to the above-mentioned technologies. In CDI, ions from an electrolyte are adsorbed on electrodes under the influence of both an applied electric field and inherent chemical surface charges [36]. When the electric field is removed, the ions held in the electric double layers (EDLs) at the electrode surface are released back into the bulk solution. Therefore, short-circuiting the electrode or applying a reverse or zero voltage during the discharge process makes it simple to regenerate the adsorbent with CDI [27]. Also, CDI's energy expenditure during its operation is low [37], but also, it has high water recoveries, low fouling, and secondary pollution prevention $[38,39]$.

Various materials including intercalation electrode materials such as MXenes [40], manganese oxides [41], Prussian blue (PB) and its equivalents [42], and carbonbased materials like graphene [43], carbon nanofibers [44], activated carbon (AC) [45], and carbon nanotubes (CNTs) [46] have been investigated as CDI electrode materials. However, carbon-based materials are the most commonly utilized materials for removing various contaminants from water (both inorganic and organic pollutants) because of their environmental friendless and cost-effective materials $[47,48]$ together with the high surface area $[49,50]$. In the removal of organic contaminants from water, CDI with $\mathrm{AC}$ electrodes has shown promising performance. Senoussi and Bouhidel [51], for example, used granular activated carbon as a CDI electrode to remove textile cationic dyes from industrial wastewater in their investigation. The maximum removal efficiency and electrosorption capacity achieved was $98 \%$ and $1.75 \mathrm{mg} / \mathrm{g}$ at $2 \mathrm{~V}$ and $10 \mathrm{~mL} / \mathrm{min}$ flowrate. Lester Yaal et al. [52] looked into using activated carbon as an electrode material in a CDI to remove salt and trace organic contaminants (bisphenol A, estrone, carbamazepine, and pentoxifylline) from water. The removal efficiency of the trace organic contaminants follows the order of bisphenol A $>$ estrone $>$ carbamazepine $>$ pentoxifylline. The removal efficiency of bisphenol A was reported to be over $90 \%$ by the authors. Based on that, we anticipate that CDI with AC electrodes can also be used to remove PQ herbicide from water since it is cationic in nature.

To the authors' knowledge, no study investigated the application of AC as CDI electrode materials for removing PQ contaminants from water. Therefore, this study investigated the suitability of commercial AC as CDI electrode materials for the removal of PQ from an aqueous solution for the first time. The influence of various CDI operational factors, such as initial concentration of $\mathrm{PQ}$, applied voltage, flowrate of the solution, treatment/charging time, and cycle stability of AC for PQ removal, was examined in batch mode experiments.

\section{Materials and Methods}

Finar Chemicals India provided the commercial AC used in this study. Before the experiments, AC was rinsed multiple times with distilled water until the effluent's $\mathrm{pH}$ was neutral, then filtered using the filter unit, and dried at $90^{\circ} \mathrm{C}$ for 3 hours. The AC used in this study was previously characterized by the literature [53]. It had $1295 \mathrm{~m}^{2} / \mathrm{g}$ BET surface area, type IV isotherms, and many microspores, and the FTIR data revealed the presence of the following bonds: C$\mathrm{O}, \mathrm{O}-\mathrm{H}, \mathrm{C}-\mathrm{H}$, and $\mathrm{O}-\mathrm{H}$. Sigma-Aldrich provided paraquat (1,1' -dimethyl-(4,4' -bipyridilium dichloride, $99.3 \%)$, carbon black (conductive material), and polytetrafluoroethylene (PTFE, $60 \mathrm{wt} \%$ dispersion in $\mathrm{H}_{2} \mathrm{O}$ ) as a binder, while Chem-Lab NV in Belgium provided ethanol (100\%). All of 


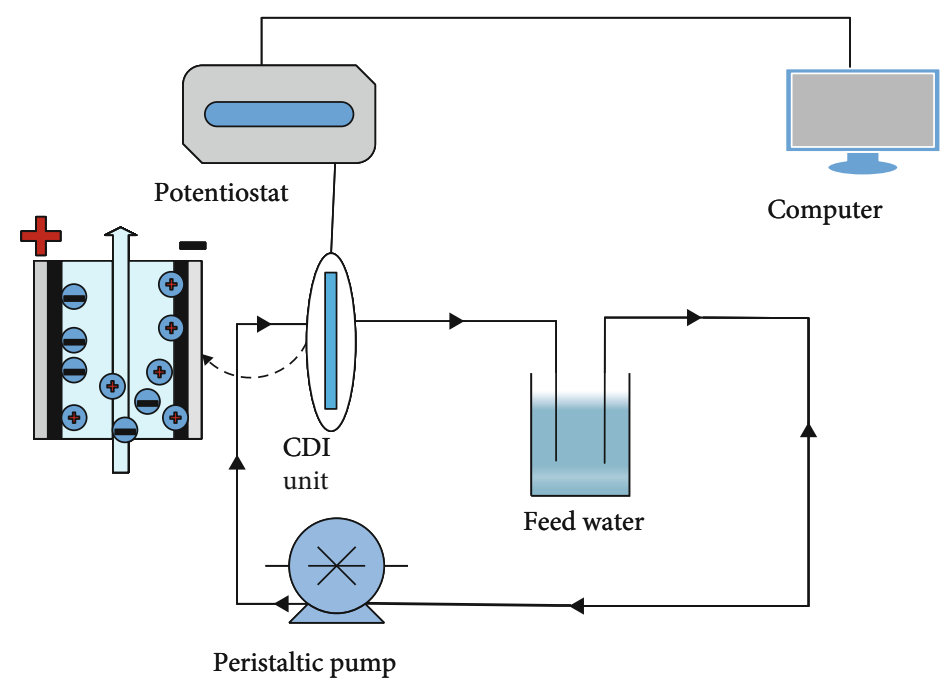

(a)

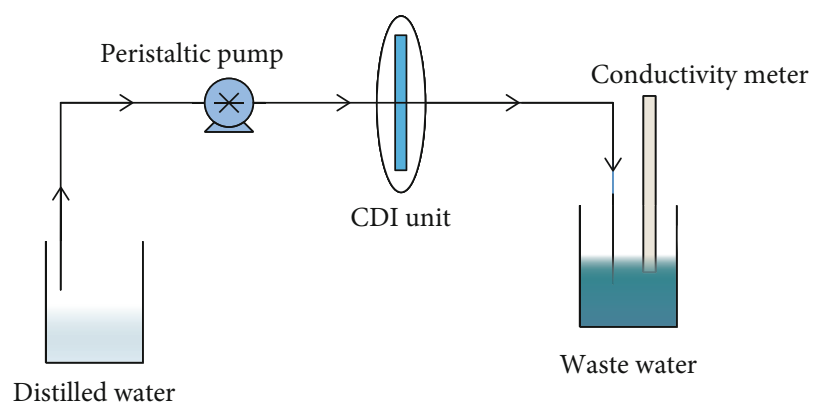

(b)

FIGURE 1: Schematic diagram of the CDI experiment setup: (a) purification; (b) regeneration.

the chemicals used were analytical grade and did not need to be purified further.

\subsection{Fabrication of AC Electrodes for CDI Cell. In this study,} an $\mathrm{AC}$ electrode was prepared by mixing $80 \mathrm{wt} \%$ of $\mathrm{AC}$ as an active material, $10 \mathrm{wt} \%$ of conductive carbon black, and 10 wt $\%$ of PTFE binder. The mixture was then added with 20 to $30 \mathrm{~mL}$ of ethanol and agitated to achieve homogeneity until a dough-like paste formed. The paste was pressed to the required thickness, cut into $3.5 \mathrm{~cm}$ by $3.5 \mathrm{~cm}$ pieces, and dried in a vacuum oven at $50^{\circ} \mathrm{C}$ overnight before being tested for leftover solvents. Finally, the electrodes were assembled into a CDI cell to test its electrosorption capacity and removal efficiency. Both AC electrodes used in the CDI tests have a combined mass of about $0.6 \mathrm{~g}$.

2.2. Capacitive Deionization Experimental Setup and Procedure. The electrosorption experiments were carried out in a batch mode in a laboratory-scale CDI reactor (Figure 1(a)) to evaluate the effectiveness of commercial AC in removing PQ. A solution tank, a peristaltic pump, a pair of electrodes, an electrochemical workstation potentiostat (equipped with IviumSoft electrochemistry software), a digital conductivity meter, and a digital $\mathrm{pH}$ meter were all part of the CDI system.
To ensure electrolyte flow and prevent short circuit, a pair of AC electrodes were put on stainless steel sheet current collectors, separated by a plastic mesh placed between the carbon electrodes. To seal the cell, rubber gaskets were added, and all of the components will be covered with plexiglass and tightened with screws. A $20 \mathrm{mg} / \mathrm{L}$ aqueous paraquat (PQ) solution was prepared by dissolving $20 \mathrm{mg}$ of paraquat dichloride in deionized water to fill a round bottom flask with $1000 \mathrm{~mL}$ of the solution. The aboveprepared solution was kept in the refrigerator at 4 to $5^{\circ} \mathrm{C}$ and was utilized for about a month without showing any signs of PQ degradation. Using the series dilution approach, a PQ solution with concentrations of 5,10 , and $15 \mathrm{mg} / \mathrm{L}$ was prepared by diluting the stock solution $(20 \mathrm{mg} / \mathrm{L})$ in a $100 \mathrm{~mL}$ volumetric flask.

During CDI operation, $40 \mathrm{~mL}$ of PQ solution with varying concentrations ( 5 to $20 \mathrm{mg} / \mathrm{L}$ ) was supplied to the CDI cell using a peristaltic pump (MasterflexLive ${ }^{\mathrm{TM}}, \mathrm{L} / \mathrm{S}^{\circledR}$ series), and the circulated feed solution was returned to the feed tank with a flowrate of 5 and $10 \mathrm{~mL} / \mathrm{min}$ To evaluate PQ herbicide electrosorption, electric potentials of 0.8 , 1.0 , and $1.2 \mathrm{~V}$ were provided to the CDI cell at electrode terminals via a potentiostat/galvanostat (Vertex.1A.EIS $1 \mathrm{~A} / 10 \mathrm{~V} / 1 \mathrm{MHz}$ EIS, Ivium Technologies, the Netherlands), as well as a control experiment (with no voltage applied) for comparison. After 1 hour, the solution in the feed tank 
was taken, and the concentration of PQ in the solution was analysed using a UV-VIS spectrophotometer. In addition, to determine the change in PQ concentration over time, $2 \mathrm{~mL}$ of PQ solution was drawn after every $10 \mathrm{~min}$ interval, and the change in PQ concentration was determined using a UV-Vis spectrophotometer. Desorption of PQ pollutants was done by recirculating distilled water through the CDI system for approximately $30 \mathrm{~min}$ (Figure 1(b)). The removal efficiency $\mathrm{RE} \mathrm{( \% )} \mathrm{and} \mathrm{electrosorption} \mathrm{capacity} \Gamma$ (mg/g) were calculated using Equations (1) and (2), respectively. Distilled water was used as a blank in this study (containing no paraquat).

$$
\begin{aligned}
& \mathrm{RE}=\frac{C_{o}-C_{f}}{C_{o}} \times 100 \%, \\
& \Gamma=\frac{\left(C_{o}-C_{f}\right)}{m} \times V,
\end{aligned}
$$

where $C_{o}$ and $C_{f}$ represent the initial and equilibrium PQ concentrations $(\mathrm{mg} / \mathrm{L})$, respectively; $V$ is the total volume of the solution $(\mathrm{mL})$; and $m$ is the mass of active material in both electrodes in grams [54].

\section{Result and Discussion}

3.1. The Measurement of the Absorption Spectrum of PQ. A UV-Vis spectrophotometer (UVmini-1240, Serial No. 10934402550, Shimadzu Corp.) equipped with a quartz cuvette with $10 \mathrm{~mm}$ of the optical path was used to measure the PQ absorption spectrum corresponding to PQ concentrations of $2,4,6,8,10,12,14,16,18$, and $20 \mathrm{mg} / \mathrm{L}$. The used UV-Vis emits electromagnetic light with wavelengths ranging from 190 to $1100 \mathrm{~nm}$. The UV-Vis spectrophotometer method was used to determine the concentration of the solution, with the absorption of light by the solution being a function of concentration. The standard paraquat calibration curve depicts the linear relationship between concentration and absorbance (Figure 2).

After CDI experiments, the equilibrium concentration of paraquat herbicide was measured using the calibration curve of paraquat standard for paraquat concentrations ranging from 2 to $20 \mathrm{mg} / \mathrm{L}$, as shown in Figure 2. In determining the paraquat solution's absorption spectrum pattern between 190 and $640 \mathrm{~nm}$, the solution's maximum wavelength data was $257.5 \mathrm{~nm}$. The maximum wavelength determined was used for later PQ absorption spectrum solution measurements.

3.2. CDI Performance. Electrosorption tests were carried out to study the CDI performance on the PQ removal from water using commercial AC electrodes. The variable CDI operational parameters investigated were concentration (5, $10,15$, and $20 \mathrm{mg} / \mathrm{L})$, applied voltage $(0.8,1.0$, and $1.2 \mathrm{~V})$, flowrate of 5 and $10 \mathrm{~mL} / \mathrm{min}$, treatment/charging time (10, $20,30,40,50$, and $60 \mathrm{~min}$ ), and cycle stability of AC electrode for PQ removal for comparison.

3.2.1. Effect of Voltage on the PQ Removal. At a flowrate of $5 \mathrm{~mL} / \mathrm{min}$, Figure 3 depicts the changes in concentration

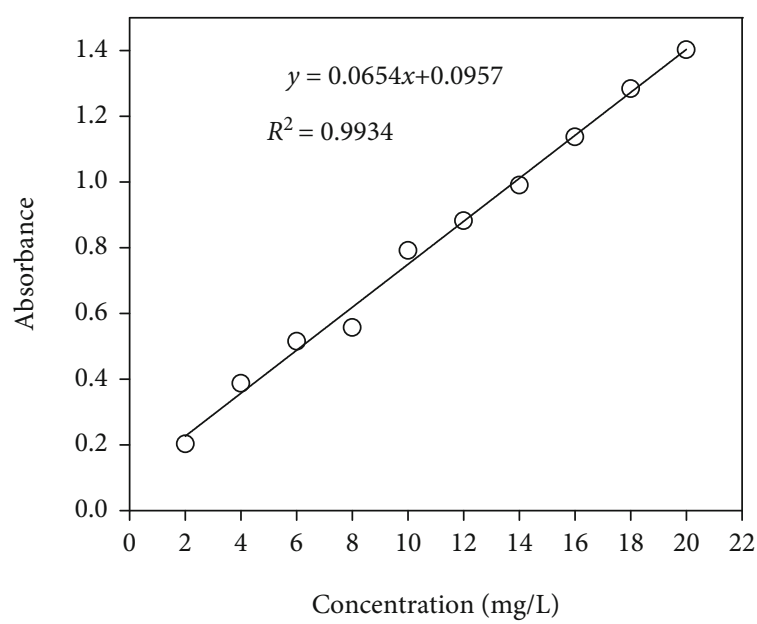

Figure 2: Calibration curve of PQ standard.

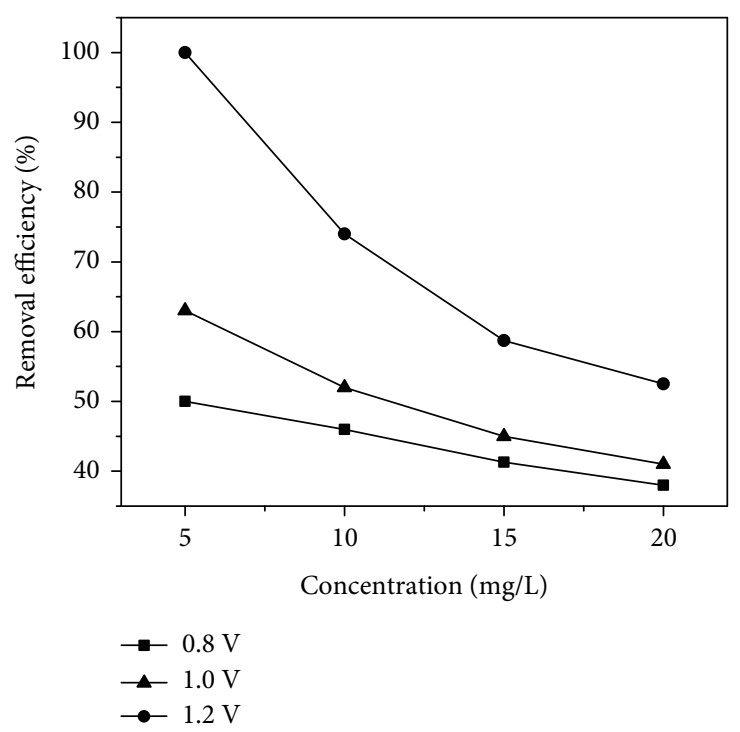

FIgURe 3: Removal efficiency of PQ at different applied voltages at a flowrate of $5 \mathrm{~mL} / \mathrm{min}$.

and removal efficiency as a function of applied voltage. The voltages above $1.2 \mathrm{~V}$ were not investigated to prevent water electrolysis and undesired faradaic reactions on the electrode [55], thus controlling the applied voltage became an important factor [56]. Because of the larger electrostatic forces caused by the increased potential, the removal efficiency rose as the applied voltage was increased from 0.8 to $1.2 \mathrm{~V}$ [57]. Herein, higher PQ removal was achieved at $1.2 \mathrm{~V}$ with the initial concentration of $5 \mathrm{mg} / \mathrm{L}$, as presented in Figure 3.

3.2.2. Effect of $P Q$ Initial Concentration on the Removal Efficiency. One of the most critical parameters affecting the operation of the CDI system is the initial concentration of the feed solution, as it might affect the effluent concentration of the outlet stream [58]. Herein, the CDI tests were carried out to investigate the influence of the initial concentration of PQ herbicide by varying the PQ concentration from 5 to 


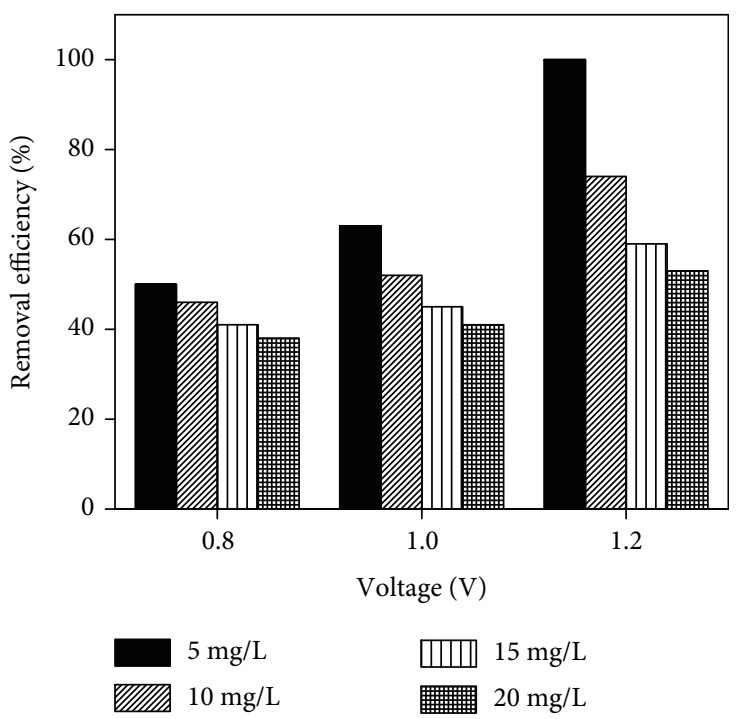

(a)

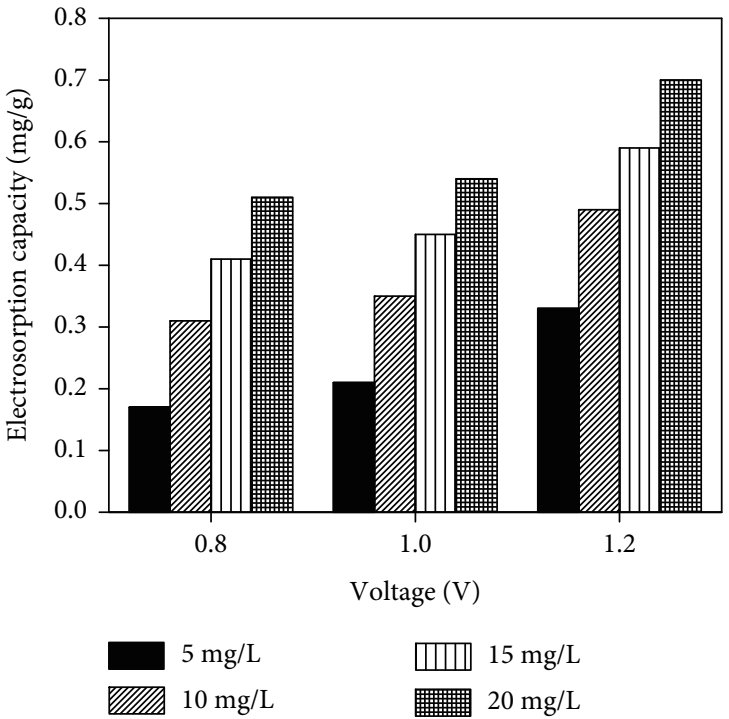

(b)

FIGURE 4: The removal efficiency and the electrosorption capacity of AC electrodes at various initial concentrations of PQ at different cell voltages and flowrate of $5 \mathrm{~mL} / \mathrm{min}$.
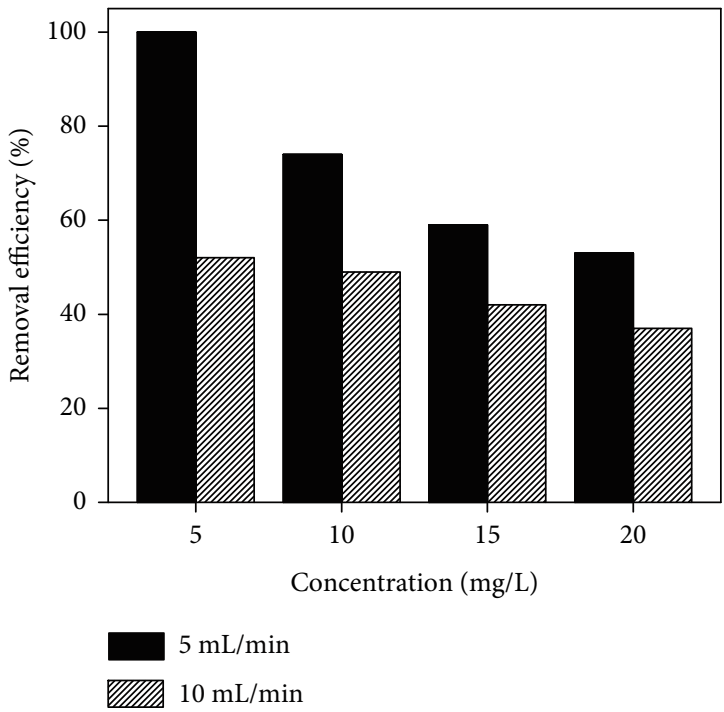
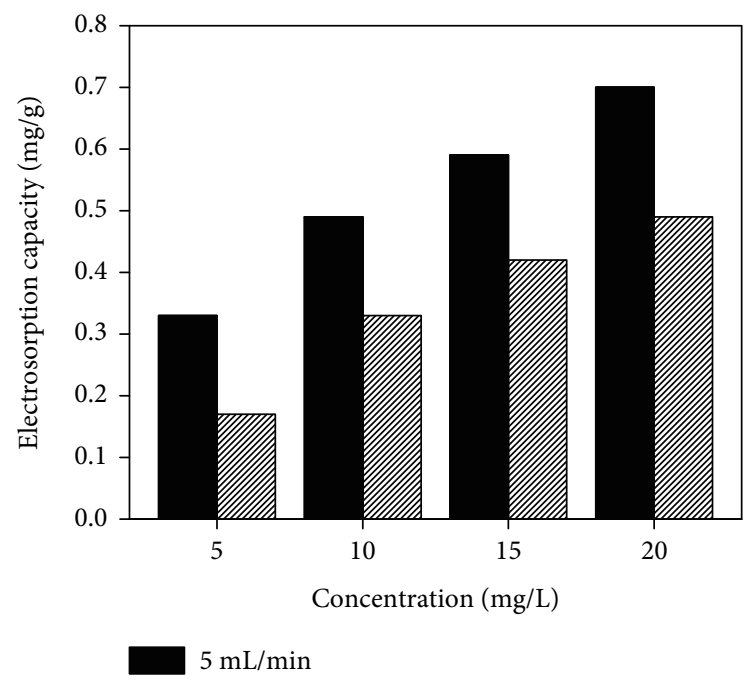

$10 \mathrm{~mL} / \mathrm{min}$

(a)

(b)

FIGURE 5: Effect of flowrate on the (a) removal efficiency and (b) electrosorption capacity of PQ onto AC electrodes at various initial feed concentrations.

$20 \mathrm{mg} / \mathrm{L}$ at a constant flowrate of $5 \mathrm{~mL} / \mathrm{min}$ and a voltage of $1.2 \mathrm{~V}$. Figure 4(a) shows that removal efficiencies declined as PQ initial concentration increased, a tendency that has been observed in several relevant studies [57]. The PQ removal efficiency of $100 \%, 74 \%, 58.7 \%$, and $52.5 \%$ was attained when using the PQ initial concentrations of $5,10,15$, and $20 \mathrm{mg} / \mathrm{L}$, respectively. The decline of removal efficiency as the initial feed concentration increases could be attributed to the quicker saturation of electric double layers (EDLs) at a higher inlet concentration $[58,59]$. Figure $4(\mathrm{~b})$ demonstrates that the electrosorption capacity is dependent on the initial concentration of the solution; electrosorption capacity increases as the concentration of the solution increases. The electrosorption capacity of the AC electrode rose by 4.1 times as the PQ concentration increases from 5 to $20 \mathrm{mg} / \mathrm{L}$. The expansion of diffuse double-layer capacity, which is mostly dependent on the electrolyte solution concentration, could explain the favourable effect of the initial concentration on the AC electrodes' electrosorption capacity [57].

3.2.3. Effects of Flowrate on PQ Removal. Flowrate is also among the important parameters to consider in CDI 


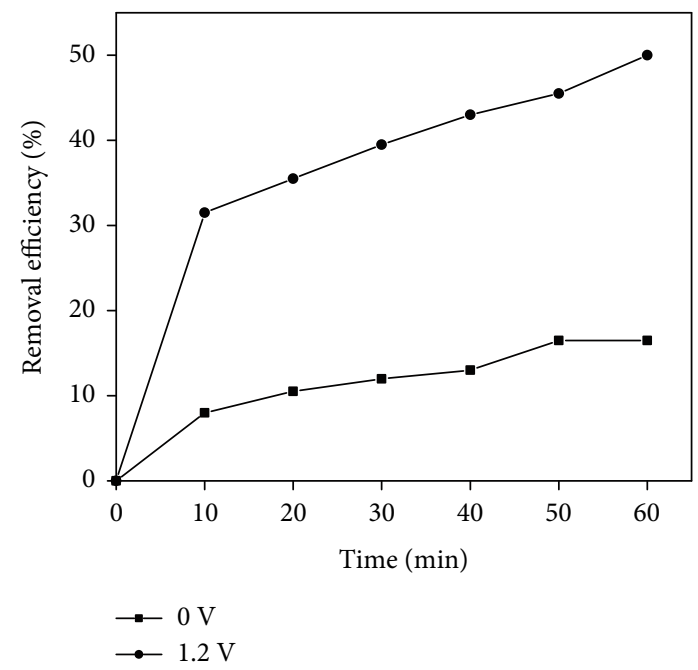

FIGURE 6: PQ removal versus time.

performance [60]. In the present study, the influence of two different flowrates on the CDI operation for removing PQ by keeping the applied voltage of $1.2 \mathrm{~V}$ was investigated. Figure 5 depicts the removal efficiency and electrosorption capacity improvement at a flowrate of $5 \mathrm{~mL} / \mathrm{min}$. Increasing the flowrate was found to decrease CDI performance because the contaminated water is not given enough time to interact with the electrode surface resulting in reduced performance as also observed by the literature [61]. Less residence time gives the ions a short time to migrate towards the electrodes for electrosorption, resulting in reduced desalination performance $[60,62]$. In this study, the flowrate of $5 \mathrm{~mL} / \mathrm{min}$ for the AC electrode is recommended as the optimum condition for the removal of PQ from water as it shows good performance in all concentrations under study.

3.2.4. Variation of $P Q$ Concentration with Time. With treatment/charging time, the ionic concentration in the solution decreases as part of the ion adsorb on the electrodes [63]. For a $5 \mathrm{~mL} / \mathrm{min}$ flowrate and an initial PQ concentration of $20 \mathrm{mg} / \mathrm{L}$, the change in PQ concentration with time at 0 and $1.2 \mathrm{~V}$ was examined (Figure 6). When a potential of $1.2 \mathrm{~V}$ was applied, the concentration dropped significantly in the first 10 minutes, indicating that PQ was rapidly electrosorbed onto the electrode surface. This could be owing to a large number of active sites on electrode surfaces that are available for electrosorption. As time increases the active sites and PQ concentration is decreased, electrosorption decreased until an electrosorption equilibrium concentration was reached. The PQ removal efficiency was up to $16.5 \%$ at $0 \mathrm{~V}$; however, when voltage of $1.2 \mathrm{~V}$ was supplied, the removal efficiency improved to $50 \%$.

3.2.5. Regeneration of Spent AC Electrodes. The electrode materials' recyclability and stability are important factors in determining the commercial success of the developed materials for industrial CDI applications. The results of recyclability testing of AC CDI electrodes using $20 \mathrm{mg} / \mathrm{L}$ of PQ feed solution are shown in Figure 7. The recyclability

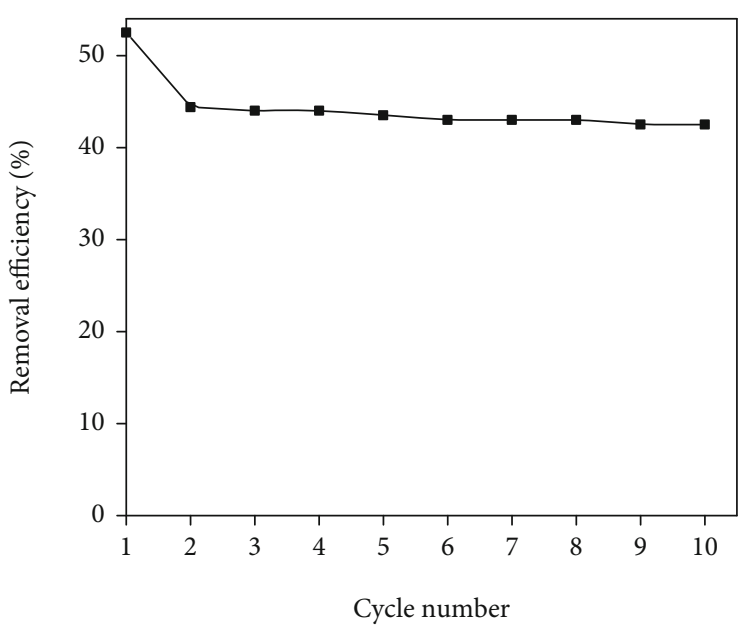

Figure 7: Reusability studies of AC electrodes at $1.2 \mathrm{~V}$ using a feed solution of $20 \mathrm{mg} / \mathrm{L}$ at $5 \mathrm{~mL} / \mathrm{min}$.

tests were carried out for ten (10) cycles, with the removal efficiency of the electrode materials being examined for each cycle. The CDI cycles were performed at $1.2 \mathrm{~V}$ and $5 \mathrm{~mL} / \mathrm{min}$ flowrate for $1 \mathrm{~h}$. The saturated AC electrode was regenerated by washing the AC electrode with distilled water for approximately $30 \mathrm{~min}$ until the conductivity of the concentrate approaches the distilled water's conductivity. As demonstrated in Figure 7, the PQ removal efficiency reduces from $52.5 \%$ to $44.4 \%$ after the first cycle of reuse and then to $42.5 \%$ after 10 cycles of reuse. The removal efficiency dropped by $19 \%$ after the electrodes have been washed and reused for 10 cycles.

\section{Conclusion}

The suitability of commercial AC as CDI electrode materials for the removal of PQ pollutants from water was studied in the current study. The effect of different experimental factors, including initial solution concentration, cell voltage, flowrate, treatment time, and cycle stability on PQ removal during the CDI operation process was studied. The result showed that CDI can be thought as an alternative for the removal of PQ from wastewater. Increasing the applied voltage (ranging from 0.8 to $1.2 \mathrm{~V}$ ) led to improved PQ removal in the feed solution while the increase in flowrate decreases the CDI performance. Furthermore, because of the limited electrosorption sites on the AC surface, an increase in $\mathrm{PQ}$ concentration had a detrimental impact on the removal efficiency of AC electrodes. Furthermore, the study demonstrates that the spent AC can be regenerated by washing it with water, which is environmentally friendly and reused for some time without a significant loss of its electrosorption capacity. Therefore, with consideration of CDI operating parameters, CDI is regarded as an alternative method for removing different organic pollutants from water, including PQ herbicide.

\section{Data Availability}

All data generated or analyzed during this study are included in this manuscript. 


\section{Conflicts of Interest}

There are no conflicts of interest declared by the authors.

\section{Acknowledgments}

The Partnership for Applied Sciences, Engineering, and Technology- (PASET-) Regional Scholarship and Innovation Fund (RSIF) under icipe, Nairobi, Kenya, funded this research.

\section{References}

[1] A. C. Sophia and E. C. Lima, "Removal of emerging contaminants from the environment by adsorption," Ecotoxicology and Environmental Safety, vol. 150, pp. 1-17, 2018.

[2] M. La Farre, S. Pérez, L. Kantiani, and D. Barceló, "Fate and toxicity of emerging pollutants, their metabolites and transformation products in the aquatic environment," TrAC, Trends in Analytical Chemistry, vol. 27, no. 11, pp. 991-1007, 2008.

[3] G. Ayre and R. Callway, Outcomes from the world summit for sustainable development, Governance for Sustainable Development, 2012.

[4] M.-f. Li, Y.-g. Liu, G.-m. Zeng et al., “Tetracycline absorbed onto nitrilotriacetic acid-functionalized magnetic graphene oxide: influencing factors and uptake mechanism," Journal of Colloid and Interface Science, vol. 485, pp. 269-279, 2017.

[5] V. Dulio and J. Slobodnik, "NORMAN-network of reference laboratories, research centres and related organisations for monitoring of emerging substances," Environmental Science and Pollution Research, vol. 16, no. S1, pp. 132-135, 2009.

[6] D. Ait Sidhoum, M. M. Socías-Viciana, M. D. UreñaAmate, A. Derdour, E. González-Pradas, and N. DebbaghBoutarbouch, "Removal of paraquat from water by an Algerian bentonite," Applied Clay Science, vol. 83-84, pp. 441-448, 2013.

[7] E. Zand, M. Baghestani, N. Nezamabadi, and P. Shimi, Application Guide of Registered Herbicides in Iran, 2010.

[8] D. S. Cocenza, M. A. de Moraes, M. M. Beppu, and L. F. Fraceto, "Use of biopolymeric membranes for adsorption of paraquat herbicide from water," Water, Air, \& Soil Pollution, vol. 223, no. 6, pp. 3093-3104, 2012.

[9] M. C. P. Recena, E. D. Caldas, D. X. Pires, and E. R. J. Pontes, "Pesticides exposure in Culturama, Brazil-Knowledge, attitudes, and practices," Environmental Research, vol. 102, no. 2, pp. 230-236, 2006.

[10] Z. Dehgani, M. Sedghiasl, M. Ghaedi, M. M. Sabzehmeidani, and E. Adhami, "Removal of paraquat from aqueous solutions by a bentonite modified zero-valent iron adsorbent," New Journal of Chemistry, vol. 44, no. 31, pp. 13368-13376, 2020.

[11] M. P. Leite, L. G. T. dos Reis, N. F. Robaina, W. F. Pacheco, and R. J. Cassella, "Adsorption of paraquat from aqueous medium by amberlite XAD-2 and XAD-4 resins using dodecylsulfate as counter ion," Chemical Engineering Journal, vol. 215-216, pp. 691-698, 2013.

[12] X.-f. Zhang, M. Thompson, and Y.-h. Xu, "Multifactorial theory applied to the neurotoxicity of paraquat and paraquat- induced mechanisms of developing Parkinson's disease," Laboratory Investigation, vol. 96, no. 5, pp. 496-507, 2016.
[13] T. E. Müller, M. E. Nunes, C. C. Menezes et al., "Sodium selenite prevents paraquat-induced neurotoxicity in zebrafish," Molecular Neurobiology, vol. 55, no. 3, pp. 1928-1941, 2018.

[14] C. P. Nanseu-Njiki, G. K. Dedzo, and E. Ngameni, "Study of the removal of paraquat from aqueous solution by biosorption onto Ayous (Triplochiton schleroxylon) sawdust," Journal of Hazardous Materials, vol. 179, no. 1-3, pp. 63-71, 2010.

[15] H. Canada, Guidelines for Canadian Drinking Water Quality-Summary Table, 2017.

[16] Y.-F. Zhang, Z.-H. Wang, X.-Q. Yao et al., "Novel tripodal-pillar[5]arene-based chemical sensor for efficient detection and removal paraquat by synergistic effect," Sensors and Actuators B: Chemical, vol. 327, p. 128885, 2021.

[17] A. Ebrahimi, M. Mansour Lakouraj, and V. Hasantabar, "Synthesis and characterization of amphiphilic star copolymer of polyaniline and polyacrylic acid based on calix[4]resorcinarene as an efficient adsorbent for removal of paraquat herbicide from water," Materials Today Communications, vol. 25, article 101523, p. 12, 2020.

[18] F. Zareei Pour, M. M. Sabzehmeidani, H. Karimi, V. Madadi Avargani, and M. Ghaedi, "Superhydrophobic-superoleophilic electrospun nanofibrous membrane modified by the chemical vapor deposition of dimethyl dichlorosilane for efficient oil-water separation," Journal of Applied Polymer Science, vol. 136, no. 24, p. 47621, 2019.

[19] Y. Li and W. A. Mitch, "Capture and reductive transformation of halogenated pesticides by an activated carbon-based electrolysis system for treatment of runoff," Environmental Science \& Technology, vol. 52, no. 3, pp. 1435-1443, 2018.

[20] R. Hailili, Z.-Q. Wang, Y. Li et al., "Oxygen vacancies induced visible-light photocatalytic activities of $\mathrm{CaCu}_{3}$ $\mathrm{Ti}_{4} \mathrm{O}_{12}$ with controllable morphologies for antibiotic degradation," Applied Catalysis. B, Environmental, vol. 221, pp. 422-432, 2018.

[21] S. Mirzaei, M. Farzadkia, A. Jonidi Jafari, and A. Esrafili, "Removal of paraquat from aqueous solution using Fenton and Fenton-like processes," Majallahi Danishgahi Ulumi Pizishkii Mazandaran, vol. 27, no. 149, pp. 151-166, 2017.

[22] C. B. Marien, C. Marchal, A. Koch, D. Robert, and P. Drogui, "Sol-gel synthesis of $\mathrm{TiO}_{2}$ nanoparticles: effect of Pluronic P123 on particle's morphology and photocatalytic degradation of paraquat," Environmental Science and Pollution Research, vol. 24, no. 14, pp. 12582-12588, 2017.

[23] R. M. Kakhki, R. Tayebee, M. Mohammadpour, and F. Ahsani, "Fast and highly efficient removal of anionic organic dyes with a new $\mathrm{Cu}$ modified nanoclinoptilolite," Journal of Inclusion Phenomena and Macrocyclic Chemistry, vol. 91, no. 3-4, pp. 133-139, 2018.

[24] L. Mehrparvar, S. Safapour, M. Sadeghi-Kiakhani, and K. Gharanjig, "A cleaner and eco-benign process for wool dyeing with madder, Rubia tinctorum L., root natural dye," International journal of Environmental Science and Technology, vol. 13, no. 11, pp. 2569-2578, 2016.

[25] J. N. Wekoye, W. C. Wanyonyi, P. T. Wangila, and M. K. Tonui, "Kinetic and equilibrium studies of Congo red dye adsorption on cabbage waste powder," Environmental Chemistry and Ecotoxicology, vol. 2, pp. 24-31, 2020.

[26] C. O. Ania and F. Beguin, "Mechanism of adsorption and electrosorption of bentazone on activated carbon cloth in aqueous solutions," Water Research, vol. 41, no. 15, pp. 3372-3380, 2007. 
[27] Z. Bai, C. Hu, H. Liu, and J. Qu, "Selective adsorption of fluoride from drinking water using NiAl-layered metal oxide film electrode," Journal of Colloid and Interface Science, vol. 539, pp. 146-151, 2019.

[28] S. Ayoob, A. Gupta, and V. T. Bhat, "A conceptual overview on sustainable technologies for the defluoridation of drinking water," Critical Reviews in Environmental Science and Technology, vol. 38, no. 6, pp. 401-470, 2008.

[29] F. Arfi, S. Safni, and Z. Abdullah, "Degradation of paraquat in gramoxone pesticide with addition of $\mathrm{ZnO}$," Molekul, vol. 12, no. 2, p. 159, 2017.

[30] N. Daneshvar, S. Aber, A. Khani, and A. Khataee, "Study of imidaclopride removal from aqueous solution by adsorption onto granular activated carbon using an on-line spectrophotometric analysis system," Journal of Hazardous Materials, vol. 144, no. 1-2, pp. 47-51, 2007.

[31] S. Kumar, W. Ahlawat, G. Bhanjana, S. Heydarifard, M. M. Nazhad, and N. Dilbaghi, "Nanotechnology-based water treatment strategies," Journal of Nanoscience and Nanotechnology, vol. 14, no. 2, pp. 1838-1858, 2014.

[32] I. Fatimah, Y. Rahmadianti, and R. Pudiasari, "Photocatalyst of perovskite CaTiO3Nanopowder synthesized from $\mathrm{CaO}$ derived from snail shell in comparison with the use of $\mathrm{CaO}$ and $\mathrm{CaCO}_{3}$," IOP Conference Series: Materials Science and Engineering, vol. 349, no. 1, p. 012026, 2018.

[33] C. Chen, W. Ma, and J. Zhao, "Semiconductor-mediated photodegradation of pollutants under visible-light irradiation," Chemical Society Reviews, vol. 39, no. 11, pp. 42064219, 2010.

[34] R. Andreozzi, V. Caprio, A. Insola, and R. Marotta, "Advanced oxidation processes (AOP) for water purification and recovery," Catalysis Today, vol. 53, no. 1, pp. 51-59, 1999.

[35] P. Gautam, S. Kumar, and S. Lokhandwala, "Advanced oxidation processes for treatment of leachate from hazardous waste landfill: a critical review," Journal of Cleaner Production, vol. 237, p. 117639, 2019.

[36] X. Gao, A. Omosebi, J. Landon, and K. Liu, "Enhancement of charge efficiency for a capacitive deionization cell using carbon xerogel with modified potential of zero charge," Electrochemistry Communications, vol. 39, pp. 22-25, 2014.

[37] M. A. Anderson, A. L. Cudero, and J. Palma, "Capacitive deionization as an electrochemical means of saving energy and delivering clean water. Comparison to present desalination practices: will it compete?," Electrochimica Acta, vol. 55, no. 12, pp. 3845-3856, 2010.

[38] M. W. Saleem and W.-S. Kim, "Parameter-based performance evaluation and optimization of a capacitive deionization desalination process," Desalination, vol. 437, pp. 133-143, 2018.

[39] J. Zhang, T. Yan, J. Fang, J. Shen, L. Shi, and D. Zhang, "Enhanced capacitive deionization of saline water using Ndoped rod-like porous carbon derived from dual-ligand metal-organic frameworks," Environmental Science: Nano, vol. 7, no. 3, pp. 926-937, 2020.

[40] P. Srimuk, F. Kaasik, B. Krüner et al., "MXene as a novel intercalation-type pseudocapacitive cathode and anode for capacitive deionization," Journal of Materials Chemistry A, vol. 4, no. 47, pp. 18265-18271, 2016.

[41] T. Wu, G. Wang, S. Wang et al., "Highly stable hybrid capacitive deionization with a MnO2Anode and a positively charged cathode," Environmental Science \& Technology Letters, vol. 5, no. 2, pp. 98-102, 2018.
[42] J. Lee, S. Kim, and J. Yoon, "Rocking chair desalination battery based on Prussian blue electrodes," ACS Omega, vol. 2, no. 4, pp. 1653-1659, 2017.

[43] P. Liu, T. Yan, L. Shi et al., "Graphene-based materials for capacitive deionization," Journal of Materials Chemistry A, vol. 5, no. 27, pp. 13907-13943, 2017.

[44] A. G. El-Deen, N. A. Barakat, K. A. Khalil, and H. Y. Kim, "Development of multi-channel carbon nanofibers as effective electrosorptive electrodes for a capacitive deionization process," Journal of Materials Chemistry A, vol. 1, no. 36, pp. 11001-11010, 2013.

[45] J. Elisadiki, T. E. Kibona, R. L. Machunda, M. W. Saleem, W.-S. Kim, and Y. A. Jande, "Biomass-based carbon electrode materials for capacitive deionization: a review," Biomass Convers Biorefin, vol. 10, no. 4, pp. 1327-1356, 2020.

[46] L. Wang, M. Wang, Z.-H. Huang et al., "Capacitive deionization of $\mathrm{NaCl}$ solutions using carbon nanotube sponge electrodes," Journal of Materials Chemistry, vol. 21, no. 45, pp. 18295-18299, 2011.

[47] T. Alfredy, Y. A. C. Jande, and T. Pogrebnaya, "Removal of lead ions from water by capacitive deionization electrode materials derived from chicken feathers," J. Water Reuse Desalination, vol. 9, no. 3, pp. 282-291, 2019.

[48] A. Derylo-Marczewska, M. Blachnio, A. W. Marczewski, A. Swiatkowski, and B. Buczek, "Adsorption of chlorophenoxy pesticides on activated carbon with gradually removed external particle layers," Chemical Engineering Journal, vol. 308, pp. 408-418, 2017.

[49] S. Porada, L. Borchardt, M. Oschatz et al., "Direct prediction of the desalination performance of porous carbon electrodes for capacitive deionization," Energy \& Environmental Science, vol. 6, no. 12, pp. 3700-3712, 2013.

[50] X. Xu, L. Pan, Y. Liu, T. Lu, Z. Sun, and D. H. Chua, "Facile synthesis of novel graphene sponge for high performance capacitive deionization," Scientific Reports, vol. 5, no. 1, pp. 1-9, 2015.

[51] H. Senoussi and K.-E. Bouhidel, "Feasibility and optimisation of a batch mode capacitive deionization (BM CDI) process for textile cationic dyes (TCD) removal and recovery from industrial wastewaters," Journal of Cleaner Production, vol. 205, pp. 721-727, 2018.

[52] S. E. Lester Yaal, E. Razi, and Z. Ines, "Capacitive deionization for simultaneous removal of salt and uncharged organic contaminants from water," Separation and Purification Technology, vol. 237, p. 116388, 2020.

[53] T. H. Sufiani Omari, T. Katsuya, L. Machunda Revocatus, and A. C. Jande Yusufu, "Enhanced electrosorption capacity of activated carbon electrodes for deionized water production through capacitive deionization," Separation and Purification Technology, vol. 247, p. 116998, 2020.

[54] Z. Y. Leong and H. Y. Yang, "Porous carbon hollow spheres synthesized via a modified Stöber method for capacitive deionization," RSC Advances, vol. 6, no. 58, pp. 53542-53549, 2016.

[55] S. Porada, R. Zhao, A. Van Der Wal, V. Presser, and P. Biesheuvel, "Review on the science and technology of water desalination by capacitive deionization," Progress in Materials Science, vol. 58, no. 8, pp. 1388-1442, 2013.

[56] J. Oladunni, J. H. Zain, A. Hai, F. Banat, G. Bharath, and E. Alhseinat, "A comprehensive review on recently developed carbon based nanocomposites for capacitive deionization: from theory to practice," Separation and Purification Technology, vol. 207, pp. 291-320, 2018. 
[57] S. Jiang, H. Wang, G. Xiong, X. Wang, and S. Tan, "Removal of nitrate using activated carbon-based electrodes for capacitive deionization," Water Supply, vol. 18, no. 6, pp. 2028-2034, 2018.

[58] C. Huyskens, J. Helsen, and A. B. de Haan, "Capacitive deionization for water treatment: screening of key performance parameters and comparison of performance for different ions," Desalination, vol. 328, pp. 8-16, 2013.

[59] S. A. Hawks, A. Ramachandran, S. Porada et al., "Performance metrics for the objective assessment of capacitive deionization systems," Water Research, vol. 152, pp. 126-137, 2019.

[60] E. C. Kumbur, E. Agar, B. Akuzum, and L. Agartan, "Impact of flow configuration on electrosorption performance and energy consumption of CDI systems," Journal of Water Supply: Research and Technology-AQUA, vol. 69, no. 2, pp. 134-144, 2020.

[61] L. Agartan, K. Hantanasirisakul, S. Buczek et al., "Influence of operating conditions on the desalination performance of a symmetric pre-conditioned $\mathrm{Ti}_{3} \mathrm{C}_{2} \mathrm{~T}_{\mathrm{x}}$-MXene membrane capacitive deionization system," Desalination, vol. 477, p. $114267,2020$.

[62] M. Mossad and L. Zou, "A study of the capacitive deionisation performance under various operational conditions," Journal of Hazardous Materials, vol. 213-214, pp. 491-497, 2012.

[63] W. Huang, Y. Zhang, S. Bao, and S. Song, "Desalination by capacitive deionization with carbon-based materials as electrode: a review," Surface Review and Letters, vol. 20, no. 6, p. $1330003,2013$. 